Stream: Inspiring Critical Thought

2017, Vol 9(2), pp. 1-14

(C) The Author(s), 2017

http://journals.sfu.ca/stream

\title{
Re-Orienting Refugee Representation? A Multimodal Analysis of Syrian Refugee Representation on the Social Media Platform Humans of New York.
}

\author{
Nicole Aarssen \\ Faculty of Communication \& Design \\ Ryerson University
}

\begin{abstract}
This paper examines a selection of photo-narratives from the social media account Humans of New York, which documented the experiences of Syrian refugees in the fall of 2015. It questions how an alternative media platform may challenge or reinforce traditional tropes utilized by mainstream media to represent a marginalized group such as Syrian refugees. Codes were developed from the literature review on Orientalism, neo-Orientalism, media representations of Islam and of refugees, as well as from theories of visual social semiotics and narrative analysis. The results suggest that while alternative platforms may challenge aspects of the Orientalist discourse, this discourse is also seen to adapt and persist through more subtle manifestations. The HONY audience is more likely to affirm representations that fit within the neoliberal notion of who is an acceptable or "worthy" refugee.
\end{abstract}

Keywords
Refugee, representation, Orientalism, discourse, Humans of New York

\section{Introduction}

This study explores how the Syrian refugee crisis is represented through the social media account Humans of New York. Dogra (2013) stated: "We come to know the world through its representations. Representations do not simply re-present facts, but also constitute them" (p. 1). This study considers how deep-rooted stereotypes can be pervasive in traditional portrayals and understandings of Middle Eastern peoples, Muslims, and refugees, exploring how these depictions create a milieu of fear and anxiety around those deemed "Other." Several overlapping discourses have been historically implicated in shaping the perception of Syrian refugees: Said's (1978) framework of "Orientalism," which has been referred to as neo-Orientalism after 9/11, and enduring patterns of refugee "Othering" examined by many scholars. While these representational conventions have traditionally manifested in mainstream media outlets, this study considers how an alternative platform, social media, represents Syrian refugees.

Brandon Stanton is a web photojournalist and creator of the Humans of New York (HONY) social media account. HONY began as a photography project based in New York City, cataloguing the diversity of New Yorkers and later including profiles of individuals in other countries. In the fall of 2015, Stanton collaborated with the United Nations Refugee Agency to document the migration of Syrian refugees as they fled their country. Although $H O N Y$ has an audience of over 23 million people 
on various social media platforms including Facebook, Twitter, Instagram and blogs, it is not bound by traditional media structures or any pretense to objectivity. "Alternative" media can be understood as media differing from dominant types of mass media in terms of production, distribution and content (Atton, 2001). For the purposes of this study, $H O N Y$ is considered alternative media. This study engages a selection of $H O N Y$ posts from the Syrian refugee series and compares them to the tropes of mainstream media, such as a worldview perpetuating the representational traditions of Orientalism, neo-Orientalism, and the Othering of Islam and refugees.

HONY has been lauded for humanizing Syrian Refugees. The New York Daily News reported that Stanton has a "remarkable gift of making global politics personal" (Cutler, 2015). Haltiwanger (2015) stated "HONY is helping to dispel the misconceptions surrounding refugees by revealing their humanity," which allowed audiences to "dig beneath the numbers and reveal the human stories" to empathise with distant others (Wahl-Jorgensen, 2015). This study considers if HONY disrupts stereotypes and provides an opportunity for subjects to assert agency and express themselves autonomously, or whether it serves as a channel to perpetuate Orientalist and neoOrientalist tropes of Othering. It is imperative to consider how Orientalism can be conceptualized as a discourse, with the potential to evolve and take on new guises. According to Foucault's (1972) discourse theory, discourse is a flexible, dynamic system that adapts to changing contexts rather than a fixed set of beliefs.

\section{Literature Review}

\section{Orientalism}

Edward Said's seminal publication Orientalism (1978) is a critique of the overarching discourse comprised of misrepresentations, generalizations, and stereotypes conferred upon the nonWestern world, referred to as "the East" or "the Orient." Said posited that Orientalism denotes three interdependent designations: an academic study of Oriental peoples and cultures; the creation of a binary that juxtaposes the progressive, civilized, and superior West against the backward, uncivilized, inferior East; and finally, as a Foucauldian discourse (Said, 1978, p. 1). The origins of academic Orientalism are commonly drawn from the Enlightenment period of the eighteenth century, during which Orientalist studies became widespread and legitimated within the paradigmatic pursuit of classification, modernization, and the "civilizing" mission of the West (Hiddleston, 2009, p. 8788). According to Childs and Williams (1997), the foundations of Orientalist knowledge were largely based on characterisations of violence, cruelty, decadence, laziness, irrationality, and disorder (p. 100). Furthermore, Samei (2015) noted that in the field of academic Orientalism, each study would arbitrarily confirm the same situation for other areas of the Orient, mutually affirming stereotypes and misrepresentations (p. 1147).

Another aspect of the Orientalist framework is the perception of Oriental inferiority and Western superiority (Said, 1978, p. 42). Drawing largely from Said, Hall (1992) argued that a dichotomy of "the West and the rest" was central to this discourse. The author noted "our ideas of 'East' and 'West' have never been free of myth and fantasy," and that geography is not primary in these perceptions (Hall, 1992, p. 185). Both Said and Hall stated that these misconceptions became embedded in Western understandings of the East to the extent that they became perceived as universal truths. Said (1978) also stated that it is essential to consider Orientalism as an entire discourse as per Foucault's definition of an "enormously systematic discipline" through which Europe managed and produced ideas about the Orient (p. 3). According to Foucault (1981), "in every society the production of discourse is at once controlled, selected, organized and redistributed by a certain num- 
ber of procedures" (p. 52). Orientalism operates as a discourse through a "widespread network of institutions and disciplines including anthropology, linguistics, history and physical sciences" (Dogra, 2013, p. 15). Said (1978) asserted that through this discursive tradition, the West both "manages" and "produces" the Orient, speaking and acting on its behalf rather than allowing for self-representation and autonomy (p. 3). It is also imperative to consider that Orientalism depends on a "flexible positional superiority" which maintains the power balance of the Westerner over the Orient in certain relationships and circumstances (Said, 1978, p. 7).

\section{Neo-Orientalism}

Said's Covering Islam (1982) explains how media and experts influence or distort Western perceptions. Said (1982) argued that, through media representations, Islam has been understood as a monolithic entity synonymous with terrorism and religious hysteria which has, in turn, encouraged hostility and fear surrounding Muslims. He notes that Muslims are frequently caricatured as bloodthirsty mobs and terrorists, and these portrayals can be traced back to outdated academic descriptions of Islamic societies (Said, 1982, p. 4-6). While Said's work highlights the legacy of Orientalism in twentieth-century media, several scholars have revitalized this discourse following the terrorist attacks of 9/11, leading to the phenomenon of neo-Orientalism. According to Altwaiji (2014), 9/11 was a pivotal moment in Arab-American relations, potently reviving discourses of Otherness and redeploying stereotypes of Arab Muslims as being fanatical, violent or intolerant (p. 313). The author also notes that while neo-Orientalism focuses on the Arab world and excludes other Orientalist regions on the map, it continues to rely on a conceptual binary that distinguishes Arab culture as inferior and Western culture as superior (p. 313). Furthermore, Tuastad (2003) emphasizes that neo-Orientalist discourses function to represent the Middle East conflict as one between civilization and barbarism (p. 596). Behdad and Williams (2010) suggested that neo-Orientalism occasionally utilizes the voice of Middle Eastern "native informants" who lend their authority and perceived authenticity to criticize their own cultures, implicating themselves in a discourse that degrades and positions them as Other (p. 3). According to Said (1978), Orientalism's "redoubtable durability" is the result of continuous investment in Orientalism as a system of knowledge, primarily by enabling socio-economic and political institutions which adapt to new contexts (Said, 1978, p. 7).

\section{Representations of Islam}

The media plays a significant role in the dissemination of Orientalist and neo-Orientalist discourses. Rane's (2010) study found that over three-quarters of participants from Western countries primarily rely on mainstream media outlets as their main source of information about Muslims and Islam. When media outlets employ primarily negative representations, this reliance becomes problematic. Rane, Ewart and Martinkus (2014) argued that Western media perpetuate Orientalist discourses by framing Middle Eastern culture and Islam as a religion that is "a different, strange, inferior and threatening 'Other'” (p. 155). Kamali (2001) found that news reports heighten public perception of differences by focusing on negative stories involving immigrants, honour killings, and legality of religious dress (p. 10-11). In addition, Karim (2006) argued that media coverage prioritizes sources that will reinforce stereotypes of Islam, rather than featuring diverse perspectives that challenge these representations.

Behdad and Gartland (2013) argued that photography has played a unique role in the historical perpetuation of Orientalism. Photography was crucial to the creation and preservation of "Europe's distinctively Orientalist vision of the Middle East," and continuously re-inscribed the region and its 
inhabitants within colonialist narratives (Behdad \& Gartland, 2013, p. 1-2). Titles and labels are utilized to control a viewer's interpretation of the represented subject, speak on their behalf, and to offset the "terror of uncertainty, the possibility of any intrusion by the Oriental Other into the life of the European viewer" (Behdad, 2013, p. 26). The propensity to label Eastern subjects effectively distances the viewer from those represented, silences their voices, and perpetuates the perception of "Otherness."

With the global reach and immediacy of mass media, stereotypes are now disseminated with unprecedented speed and reach (Childs \& Williams, 1997, p. 101). Most scholars consider Orientalism as the historical basis of Islamophobia, believing that mass media (and increasingly, social media) play a considerable role in rousing and intensifying it (Rane et al., 2014, p. 38-39). Nakamura (2002) argued that the perception of the Internet breaking down cultural barriers generates anxiety for Western subjects, who consequently reassert stereotypes to address these fears. Instead of overcoming difference in a post-Internet context, cultural divisions have instead been highlighted repeatedly "in order to anchor the Western viewing subject's sense of himself as a privileged and mobile viewer" (Nakamura, 2002, p.21). Therefore, advances in communication technology and increased exposure to diverse narratives may not necessarily overcome stereotypes but may reinforce them further.

\section{Representation of Refugees}

In addition to the representational tropes associated with being a largely Muslim group, Syrian refugees are also vulnerable to mass media's tendency to frame refugees in a negative, dehumanizing and distancing manner. Philo, Briant and Donald (2013) found that mass media outlets largely silence the voice of refugees and use negative language regarding policy about the acceptance of refugees (p. 56). Haynes, Deveraux and Breen (2014) identified several key negative frames in mainstream news media in the context of discourse about refugees: economic threats, social deviants, illegal aliens, and a threat to national integrity. These frames are utilized to represent refugees as "Other" and to delegitimize the system of asylum (Haynes, Deveraux \& Breen, 2014). Behrman (2014) also noted that refugees are presented as "an undifferentiated mass" that lack agency or the skills of the "settled citizenry," and are unreasonably demanding and undeserving of Western assistance (Behrman, 2014, p. 249, 268).

Bleiker, Campbell, Hutchison and Nicholson (2013) observed that media representations play a critical role in framing both public perception and political discussion of refugees (p. 402). Socialpsychological studies show that close-up, portrait-style photos are most likely to evoke feelings of compassion in viewers, whereas group shots are more likely to create emotional distance (Bleiker et al., 2013, p. 399). They found there was a tendency to show refugees in large groups and lacking recognizable facial features, leading to "visual dehumanization" (Bleiker et al., 2013, p. 406). Batziou (2011) noted that press photographs use particular techniques, such as spatial distance and expressionless faces, to frame immigrants as Other (p. 41). Most press photographs Batziou (2011) analyzed had been taken from a "safe" social distance and lacked emotional expressiveness. In effect, this "Othering" dehumanized and distanced the immigrant subjects (p. 48, 56). Conversely, Slovic (2007) suggested that putting a human face to suffering is significant for generating emotional responses and a willingness to take action (p. 83). Additionally, Batziou (2011) found that emotional expression could function as a "bridge" between the subject and viewer, allowing the viewer to identify with the subject (p. 45-48).

Similarly, scholars Jenni and Lowenstein (1997) presented the "identifiable victim effect" which suggests that subjects who can be clearly identified "produce a greater empathetic response, ac- 
companied by greater willingness to make personal sacrifices to provide aid" (p. 236). The authors suggested that when the victim's story is highly emotional and unfolding in real time it positions a victim as helpless or blameless, which increases sympathy (Jenni \& Lowenstein, 1997, p. 237). In addition, Small and Verrochi's (2009) study found people experienced sadness when they viewed a sad-faced image, and were more sympathetic towards victims after being provided with a description of their plight (p. 786).

\section{Visual Social Semiotics}

The term "semiotics" denotes the study of signs, largely based on the work of Ferdinand de Saussaure and Roland Barthes. Harrison (2003) stated that the process of semiosis occurs when some content or meaning (i.e. signified) is manifested in a representation or expression (i.e. the sign) (p. 47). Lemke (1990) described social semiotics as the study of how signs are utilized to construct and understand social and communal life (p. 183). Jewitt and Oyama (2001) defined visual social semiotics as "what can be said and done with images and how the things people say and do with images can be interpreted" (p. 136). Kress and van Leeuwen (1996) developed an inventory of the main compositional structures that have been established in the tradition of visual social semiotics and analyzed how these structures shape the production of meaning (p. 1). The authors stated that an image performs several different functions simultaneously to create visual meaning. One of these functions, the interpersonal metafunction, suggests that distinct semiotic features shape the relationship between the producer and receiver of a sign (Kress \& van Leeuwen, 1996, p.42). Image features such as action, gaze, social distance, intimacy and perspectives (such as frontal and oblique angles) determined the quality of viewer engagement (Kress \& van Leeuwen, 1996, p. 43). The authors asserted that when participants look directly at the camera ("demand"), a connection forms between viewer and subject. Conversely, when the subject is looking away from the camera ("offer"), they become the "object of the viewer's dispassionate scrutiny" (Kress \& van Leeuwen, 1996, p. 119). The frontal angle invites a stronger association with viewers, implying that the subject is "one of us" (Harrison, 2003, p.53). Kress and van Leeuwen (1996) also asserted that the subject's distance from the camera determines the level of intimacy the viewer associates with them (p. 124). Intimate distance (a cropping of the head and face) and close personal distance (cropping the head and shoulders) both denote a stronger sense of intimacy compared to images with a far social distance (i.e. the whole figure of a subject) and public distance (torsos of many people). Therefore, intimate distance photos are more likely to generate sympathy from viewers, while photographic distance can reinforce social difference and Otherness, dehumanizing refugees.

\section{Narrative Captions \& Agency}

Traditional mass media outlets tend to perpetuate Orientalist discourse and tropes (Childs \& Williams, 1997; Behdad \& Gartland, 2013; Rane et al., 2014). Contrasted with the traditional editorial reporting style of mass media, where statements from refugees reflect a small fraction of the content in news stories, alternative/social media platforms such as $H O N Y$ provide the opportunity for a diverse source of voices. Each photo is accompanied by an excerpt of a first-person narrative provided by the subject, allowing them to assert their own voice and enact agency in representing themselves in a context that would traditionally silence them. Green and Brock (2000) found that narratives can inspire strong emotions and motivations in the reader, and that narrative experience has the power to change individual attitudes and beliefs (p. 702). Aguirre (2005) also found per- 
sonal narratives are powerful rhetorical tools, with the ability to "challenge a master narrative that seeks to portray the weak or powerless... in negative images or social contexts" (p. 147).

Allowing subjects to relay stories in their own words also disrupts the conventional practice of an editor determining a title and caption which speaks on behalf of the subject. Behdad (2013) noted that titling and labeling encourages Orientalist discourse by controlling the viewer's scope of interpretation. Alesch (2007) noted that homodiegetic (first-person) narrators wield significant power as "the very elements that make a narrative told by a homodiegetic narrator compelling-its supposed truth value, coupled with the insistence that it be accepted on its own terms-can make it disconcerting" (p. 94). Chouliaraki (2013) noted that substituting a journalist for a citizen on newer media platforms invokes greater authenticity in the act of witnessing. Rather than prioritizing the "intrinsic value of facts," the citizen witness utilizes testimony and personal opinion, which makes them "the most appropriate voice to tell the story of suffering" (Chouliaraki, 2013, p.147). Clark, Couldry, MacDonald, and Stephansen (2015) also found that narrative storytelling on digital platforms provide the opportunity for individuals to exercise agency (p. 935). However, neo-Orientalist discourse may also manifest through the testimony of the "native informant" who utilizes their authority to further perpetuate negative perceptions, lending legitimacy to stereotyped ideas (Behdad \& Williams, 2010).

\section{Methodology}

Twenty HONY photo-narratives were selected for content analysis. The sample was collected by identifying the top twenty most "liked" Instagram posts from the Syrian Refugee series, which is more likely to reflect content resonating the most with audiences. The photo-narratives were analyzed using a multi-modal approach of content analysis which combined narrative and visual social semiotic analysis. The codes utilized were developed from scholars referenced in the literature review, in addition to emergent codes from the data sample. All findings were coded in a codebook. The visual elements coded were: number of Represented Participants (RPs), facial expression, gaze, distance, angle, as well as the presence of a visual marker of difference. The textual elements coded were: asserting agency, lacking agency, "refugeeness," humanism, terrorism/radicalism, and "native informant" view.

\section{Findings}

Overall, the most common manner of visual representation in the HONY sample was an individual male RP with a happy expression, "demand" gaze, shot from a far social distance and frontal angle, with no visual marker of difference. The most common theme in the narrative was "refugeeness," followed by "humanity." The full findings are shown in Tables 1 and 2.

\section{Analysis}

The initial findings suggest that the representation on $H O N Y$ challenges traditional representation in many ways. However, Orientalism is a discourse, and is not uniform or monolithic. Expressions of Orientalism have been shown to evolve through different historical contexts. Some of these more flexible displays of Orientalism can be found in the data sample.

It is noteworthy that there were no depictions of large groups in the sample and only two occurrences of medium sized groups. Most of the HONY images in the sample featured individual subjects or small groups of two to three people. This finding was contrary to the representational tradition 
of visually dehumanizing refugees by portraying them in large groups with no discernible facial features. Furthermore, it conflicts with Said's (1978) statement that "in newsreels or news-photos, the Arab is always shown in large numbers. No individuality, no personal characteristics or experiences" (p. 287). Escobar (1995) noted that in mass media, refugees and Middle Eastern "Others" are frequently represented as "an undifferentiated mass of dark people, the 'teeming masses' of the Third World" (p. 210). In the HONY sample, however, they are portrayed predominantly as individuals and in small groups, with identifiable emotional expressions and unique narratives shared through the captions.

Table 1. Summary of Visual Modality

\begin{tabular}{|c|c|c|c|}
\hline \multicolumn{4}{|c|}{ Visual Modality } \\
\hline Category & Codes & Total & $\%$ \\
\hline \multirow[t]{4}{*}{ Number of RPs } & 1 & 11 & 55 \\
\hline & 2 to 3 & 7 & 35 \\
\hline & 4 to 10 & 2 & 10 \\
\hline & $10+$ & 0 & I \\
\hline \multirow[t]{4}{*}{ Emotion/Expression } & Happy/positive & 10 & 50 \\
\hline & Sad/negative & 4 & 20 \\
\hline & Neutral & 5 & 25 \\
\hline & Cannot see face & 1 & 5 \\
\hline \multirow[t]{3}{*}{ Gaze } & Offer & 2 & 10 \\
\hline & Demand & 17 & 85 \\
\hline & Cannot see face & 1 & 5 \\
\hline \multirow[t]{6}{*}{ Distance } & Intimate & 0 & / \\
\hline & Close Personal & 7 & 35 \\
\hline & Far Personal & 2 & 10 \\
\hline & Close Social & 1 & 5 \\
\hline & Far Social & 8 & 40 \\
\hline & Public & 2 & 10 \\
\hline \multirow[t]{2}{*}{ Horizontal Angle } & Frontal & 20 & 100 \\
\hline & Oblique & 0 & I \\
\hline \multirow[t]{3}{*}{ Gender } & Male & 10 & 50 \\
\hline & Female & 3 & 15 \\
\hline & Mixed & 7 & 35 \\
\hline \multirow{2}{*}{$\begin{array}{l}\text { Visual Marker of } \\
\text { Difference/Exoticism }\end{array}$} & Yes & 7 & 35 \\
\hline & No & 13 & 65 \\
\hline
\end{tabular}


Table 2. Summary of Textual Modality

\begin{tabular}{|l|c|c|}
\hline \multicolumn{3}{|c|}{ Textual Modality } \\
\hline Category & Total & $\mathbf{\%}$ \\
\hline Asserting Agency & 3 & 15 \\
\hline Lacking Agency & 7 & 35 \\
\hline "Refugeeness" & 17 & 85 \\
\hline Humanity/humanism & 10 & 50 \\
\hline Terrorism/radicalism & 0 & $/$ \\
\hline "Native informant" view & 4 & 20 \\
\hline "Western intervention" (Brandon) & 6 & 30 \\
\hline
\end{tabular}

Furthermore, the gaze and angle that are predominantly featured in the sample reflect an empowering mode of representation that is empowering for subjects. The entire sample represented Syrian refugee subjects from a horizontal frontal angle, creating a strong sense of viewer participation and indicating that the RP is "one of us" (Harrison, 2003, p.53). Furthermore, nearly all the samples featured RPs with the more inclusive and empathy inducing "demand" gaze rather than the more detached and scrutinizing "offer" gaze (Jennie \& Loewenstein, 1997; Kress \& van Leeuwen, 1996). It is interesting to note that half of the sample featured RPs with a happy expression whereas only four posts presented RPs with a sad expression. While the literature suggests that subjects with sad faces are more likely to evoke feelings of sympathy, the prevalence of happy-faced RPs may suggest that invoking sympathy is not the sole purpose of the HONY series. Rather, the more positive facial expressions may serve as a commentary on Syrian refugees' perseverance and attempt to cope with a difficult reality. The predominance of happy expressions may also be the outcome of Stanton's choice to interview refugees who had been cleared for resettlement in the United States and who are therefore shown to be hopeful for the future. Regardless, it is noteworthy that nearly all the visual representations contained discernible facial features and expressions that "humanize" refugees-only one post contained an RP whose face could not be seen because the photo was shot from behind the subject (Small \& Verrochi, 2009).

The distance between the subjects and the camera varied considerably, with a variety of camera distances used to portray the RPs in this sample. While mainstream representations of refugees tend to be from a "public" distance (torsos of several people), only two HONY samples used this type of shot. The majority were closer to the subjects, inviting a greater sense of intimacy. There was also a high degree of diversity surrounding the gender of the RPs. Dogra (2013) asserted that many NGO campaigns focus on images and narratives of children and women because of their perceived innocence or helplessness. Malkki (1996) also noted the prominence of women and children used for visual representations of refugees. She argued that this pattern reflects not only the reality that most refugees are women and children, but also "the institutional, international expectation of a certain kind of helplessness as a refugee characteristic" (Malkki, 1996, p. 388). Half of the sample featured male subjects, while only three posts represented sole female subjects. The remaining seven contained a mixture of male and female. This finding suggests that HONY diverges from traditional modes of refugee representation, which employ "feminization" to reinforce tropes of refugees, such as helplessness and being in need. Although this study did not initially code for the presence of children in the HONY posts, it appeared that eight of twenty posts (40\%) also contained children. Finally, approximately one third of the sample contained a visual marker of difference. 
Although such visual markers may function to highlight "Otherness," it is important that representations do not erase cultural difference entirely in attempts to bridge the cultural variance between groups. Furthermore, many photos that contained such visual markers were some of the most "liked" by viewers.

Malkki (1996) pointed out that photographs and other visual representations of refugees are far more common than print representations of what particular refugees have said (p. 386). The author also noted that the personal accounts of refugees tend to be disqualified "almost a priori" while the discourses of other agents such as refugee experts or relief officials tend to monopolize narratives (Malkki, 1996, p. 386). Consequently, HONY is significant because it has provided a platform that allows Syrian refugees to form their own narratives instead of being silenced by traditional experts and media. However, it is significant to note that nearly one third of the sample contained a narrative from Brandon Stanton, the photographer, rather than the subject. This deviation from the usual formula suggests that viewers may be more inclined to "like" a post when it contains a Western perspective validating the refugee experience. Malkki (1996) noted that humanitarian discourse often includes a Western "intervener" role that emphasizes refugees as objects requiring assistance or management (p. 377). This is demonstrated in one photo-narrative featuring a comment from President Barack Obama. It was the most "liked" post in the entire sample, and the inclusion of the president's comment increased the newsworthiness of the post. Daniel (2002) points out that newsworthiness is highly implicated in refugee discourse and also "determines which stories will be counted as 'true,' 'just,' and 'deserving'" (p. 280). The stamp of validation evoked by the president is significant because it appears in a post about a male in a conventional profession who, in his original post, asserted his success and desire to continue working and being productive in America. This finding suggests that ideas of productivity, success and authoritative validation are involved in viewers' decision to "like" a particular representation of a refugee. Although the narrative provided by "the Scientist" suggests refugee empowerment, the underlying discourse is grounded in neoliberal values of individualism and self-reliance.

Chouliaraki (2006) is critical of disaster news that "dehumanises sufferers through the absence of their agency" (p. 97). The code "asserting agency" occurred only three times in this sample, while the code "lacking agency" occurred seven times, or more than twice as often. Regardless, it was significant for the sample to reveal any instance of refugees asserting agency and expressing competency. Said (2000) noted that the word "refugee" had become political, suggesting large groups of "bewildered people requiring urgent international assistance" (p. 181). The majority of the sample spoke about their experience as a refugee in their narrative caption, coded as "refugeeness." Given that Stanton's role was to document the lives of refugees it is unsurprising that the narratives are predominantly about refugee experience, even if this does reinforce viewers' understanding of the subjects as such. Greater emphasis on the diversity of narratives may help challenge representational tropes. Nevertheless, almost half of the narratives in the sample contained an emphasis of humanity and humanism, which invokes a sense of a mutual human condition rather than emphasizing difference and distance. Van Schaik (2016) found that in a sample of mass media representations of Syrian refugees, only $14 \%$ were coded as "individualized people like us" (p. 51). These types of representations speak positively about refugees, emphasizing acceptance and inclusion; repositioning them from being "the backward Other" to "persons like us" (van Schaik, 2016, p. 51). While themes of sameness were found in only a fraction of mainstream representations of Syrian refugees, these values were present in the majority of posts in the HONY sample.

Literature on Orientalism and neo-Orientalism establishes that, in contemporary Orientalist discourse, terrorism and religious radicalism are assumed to be inherent to Islam and Middle Eastern cultures (Altwaiji, 2014; Said, 1982). However, the sample for HONY contained no references to re- 
ligious radicalism, terrorism, or ISIS. However, there were some instances in the sample that reflected the "native informant" function of neo-Orientalism, wherein a subject from the Middle East expresses a negative opinion of the religion or region of origin. For example, Sample 13 states: "I'm not going to turn on the television again. I'm done with religion and politics forever." This narrative suggests that the subject is turning their back on their religion and country of origin. At the same time, it alludes to the United States being a safe haven or an object of salvation, one where religious and political violence does not exist. Other narratives did not essentialize their own culture or denigrate the region, but several narratives made reference to violence, upheaval, or danger. For example, the narrative from Sample 14 references "the war" and the following bombings, while Sample 9 stated that a sniper shot their youngest brother. Although these narratives involve geo-political unrest that is out of the subject's control, such narratives may also reinforce stereotypes about Arabs, specifically images of disorder and violence.

Furthermore, while most $H O N Y$ posts feature Syrian refugees as narrators, several posts presented Stanton's voice rather than the subject. As well, all posts are framed through the lens of a white, Western male. Stanton mobilizes efforts to fund various groups (including Syrian refugees), but he also gains fame and popularity in the process of displaying his subjects and relaying their personal narratives or struggles. One critic in The New Yorker, suggested that HONY's refugee series could be voyeuristic, engaging in the "cavalier consumption of others" and mirroring the tendency for the West to essentialize and fetishize the Orient (Cunningham, 2015). Theories such as the identifiable victim effect suggest that witnessing vivid suffering inspires greater empathy and action. However, Adams (1998) suggests that globalization has produced information systems that allow us to witness the suffering of distant others as a spectacle with "emotional involvement but without action, as if studying historical tragedies rather than current events" (p. 103). In a discussion of Bauman's social spaces, Adams (1998) asserted that modern mass media creates an "ultimate aesthetic space" which is separate from moral and cognitive space, alienating subjects and reducing others to "spectators and unwitting performers" (p. 103). Although the account has been conceptualized as alternative media rather than mass media, it is possible that a similar disjuncture between moral, cognitive, and aesthetic space could occur in HONY.

Additionally, it is important to note the tie between Orientalism and neoliberalism in the sample. The two most "liked" posts were from "white-passing" men who asserted agency, intelligence, and success. Sample 18 showed a reply from Barack Obama welcoming a refugee to the United States who had a great deal of accomplishments and successes. Sample 3 portrayed a man who taught himself German by studying for "seventeen hours a day" until he gained his Austrian citizenship. These narratives were the most validated by the audience, which may indicate that refugees are accepted and appreciated for their perceived economic value rather than for their plight. Neoliberalism is highly involved in the construction of citizenship with an emphasis on the enterprising individual, and thus comes into play in the representation and interpretation of refugees seeking citizenship. Within this framework, Syrian refugees may be more accepted by audiences (i.e. more "liked" on social media) when emphasizing neoliberal "worthiness" instead of empathic sameness. In an interview with CNN, Stanton noted that refugees who were approved for resettlement in the United States usually benefitted from exceptional circumstances, were highly educated (many had a $\mathrm{PhD}$ ), or had a specialized accreditation (December 11, 2015). In effect, neoliberal ideology is often used in nationalistic and xenophobic rhetoric, intensifying the struggle for Syrian refugees.

Finally, narratives about refugees-including those in $H O N Y$ - often lack accountability for colonial actions and rarely criticize such legacies for creating crises abroad. While HONY's anecdotal narratives from individual refugees may provide a more humanizing perspective, such stories also justify aid by minimizing historical context and the West's role in the crisis. This tendency of West- 
ern "historical amnesia" is not unprecedented. Foucault noted that during Vietnamese refugee crisis, Western intervention in former colonies often resulted in enduring tensions and antagonisms which displaced citizens, forcing many to declare themselves refugees. However, the significance of Western responsibility is rarely included in prominent narratives of refugee movement, which makes this omission a component of the discourse itself. Failing to acknowledge the weight of colonial actions while continuously representing refugee crises as a result of the "inferior" culture or region perpetuates Orientalist discourse (Bagelman, 2015; Kelly, 2010).

\section{Conclusion}

There are many breakthrough elements in HONY's representation of Syrian refugees. HONY presents RPs as a diverse group with a variety of experiences and emotions rather than an undifferentiated mass. Participants can provide their own narratives instead of having a Western authority represent their experience; however, Orientalism's discursive nature allows the West to change the nature of its relationship while maintaining its "superior" status (Said, 1978, p. 7).

While most HONY posts featured Syrian refugees as narrators, several posts presented Stanton's voice rather than the subject. All the posts are framed through the lens of a white, Western male. Theories such as the identifiable victim effect suggest that witnessing vivid suffering inspires greater empathy and action, but Adams (1998) suggests that globalization has produced information systems that allow us to witness suffering as a spectacle, reducing persons to "spectators and unwitting performers" (p. 103). Although HONY has been conceptualized as alternative media, a disjuncture between moral, cognitive and aesthetic space may occur when narratives are only framed through a Western lens.

Additionally, the emphasis on Orientalism and neoliberalism in such narratives imply that refugees are accepted and appreciated for their economic contributions instead of their plight. Since neoliberalism is highly involved in the construction of citizenship and often accompanies potent nationalistic and xenophobic rhetoric, it may amplify the problems that refugees face regularly.

Lastly, narratives about refugees fail to acknowledge or incorporate a criticism of colonial actions. While HONY's narratives of may provide humanizing perspectives, emphasizing such stories as justification for aid minimizes historical context of the event and Western responsibility. Failing to acknowledge the weight of colonial actions and continuously attributing refugee crises to the "inferior" nature of these regions further perpetuates the Orientalist discourse (Bagelman, 2015; Kelly, 2010).

This study focused on Syrian refugees as represented through a social media platform using visual semiotic methods; however, it did not attempt to gauge the affective response of the audience in relation to these representations. This limitation suggests the need for further research on this topic, especially concerning public perception. The study may also benefit researchers wishing to compare representations between mass media outlets and alternative or independent media.

This study argued that alternative media platforms can challenge some aspects of Orientalist representation, but Orientalist rhetoric often adapts and manifest in new ways (e.g. through neoliberal ideology). An attempt to bridge distance and Otherness is undermined by presenting refugees as economic value in which a host country can benefit. Furthermore, a lack of accountability for the West's role in the conflict leads to the persistence of Orientalist discourse and dehistoricizes events to maintain a guise of superiority in certain contexts. The findings also reveal that the continuity of this discourse may be subtle, such as when online communities tacitly affirm existing subject positions. By considering the techniques of representation and their historical relationships to power, 
this study offers insight into how social media can challenge aspects of Orientalist discourse while revealing its tendency to adapt to new channels and socio-political environments.

\section{References}

Adams, P. (1998). Network topologies and virtual place. Annals of the Association of American Geographers, 88(1), 88-106.

Altwaiji, M. (2014). Neo-orientalism and the neo-imperialism thesis: Post-9/11 US and Arab world relationship. Arab Studies Quarterly, 36(4), 313-323.

Alesch, J. S. (2007). Marguerite Yourcenar: The Other/reader. Summa Publications, Inc.

Aguirre, J., Adalberto. (2005). The personal narrative as academic storytelling: A chicano's search for presence and voice in academe. International Journal of Qualitative Studies in Education, 18(2), 147-163.

Atton, C. (2001). Alternative media. London, UK: Sage.

Bagelman, J. (2015). Foucault and the 'current' refugee crisis. OpenDemocracy. Retrieved from https://www.opendemocracy.net

Barthes, R., \& Heath, S. (1978). Rhetoric of the Image. In Image, Music, Text (pp. 151-163). London, UK: Hill and Wang.

Batziou, A. (2011). Framing 'otherness' in press photographs: The case of Immigrants in Greece and Spain. Journal of Media Practice, 12(1), 41-60.

Behrman, S. (2014). Accidents, agency and asylum: Constructing the refugee subject. Law and Critique, 25(3), 249-270.

Behdad, A. (2013). The Orientalist Photograph. In Behdad, A., \& Gartlan, L. (Eds.) Photography's Orientalism: New essays on colonial Representation (pp. 11-31). Los Angeles, USA: Getty Research Institute.

Behdad, A., \& Gartlan, L. (2013). Photography's Orientalism: New essays on colonial Representation. Los Angeles, USA: Getty Research Institute.

Behdad, A. \& Williams, J. (2010). Neo-Orientalism. In B.T. Edwards \& D.P. Gaonkar (Eds.), Globalizing American Studies (pp. 283-298). Chicago, USA: University of Chicago Press.

Bleiker, R., Campbell, D., Hutchison, E., \& Nicholson, X. (2013). The Visual Dehumanisation of Refugees. Australian Journal of Political Science, 48(4), 398-416.

Clark, W., Couldry, N., MacDonald, R., \& Stephansen, H. (2015). Digital platforms and narrative exchange: Hidden constraints, emerging agency. New Media \& Society, 17(6), 919-938.

Childs, P., \& Williams, R. J. P. (1997). An Introduction to Post-Colonial Theory. London, UK: Prentice Hall.

Chouliaraki, L. (2013). The Ironic Spectator: Solidarity in the age of post-humanitarianism. Cambridge, UK: Polity.

Cutler, J. (2015, October 15). 'Humans of New York' creator Brandon Stanton relays emotional journey of Syrian refugees. New York Daily News.

Cunningham, V. (2015, November 3). Humans of New York and the cavalier consumption of others. The New Yorker. Retrieved from http://www.nydailynews.com

Daniel, E.V. (2002). The Refugee: A discourse on displacement. In J. McClancy (Ed.), Exotic No More: Anthropology on the Front Lines (pp. 270 - 286). Chicago, USA: University of Chicago Press.

Dogra, N. (2012). Representations of global poverty: Aid, development and international NGOs (Vol. 6). London, UK: IB Tauris.

Escobar, A. (2011). Encountering development: The making and unmaking of the third world. Princeton, USA: Princeton University Press. 
Foucault, M. (1972). The archaeology of knowledge. London, UK: Tavistock Publications.

Foucault, M. (1981). The order of discourse. In R. Young (Ed.), Untying the text: a post-structural anthology (pp. 48-78). Boston, USA: Routledge \& Kegan Paul.

Green, M., \& Brock, T. (2000). The role of transportation in the persuasiveness of public narratives. Journal of Personality and Social Psychology, 79(5), 701-721.

Harrison, C. (2003). Visual social semiotics: Understanding how Still Images Make Meaning. Technical Communication, 50(1), 46-60.

Hall, S. (1992). The West and the Rest: Discourse and Power. In S. Hall \& G. Bram (Eds.), Formations of Modernity (pp. 275-331). Cambridge, UK: Polity Press.

Haltiwanger, J. (2015, September 25). 'Humans of New York' uses emotional posts to reveal the humanity of Refugees. Elite Daily. Retrieved from http://elitedaily.com

Haynes, A., Devereux, E., \& Breen, M. J. (2006). Fear, framing and foreigners, The othering of immigrants in the Irish print media. Critical Psychology, 16, 100-21.

Hiddleston, J. (2009). Understanding Postcolonialism. London, UK: Routledge.

Jenni, K., \& Loewenstein, G. (1997). Explaining the Identifiable Victim Effect. Journal of Risk and Uncertainty, 14(3), 235-257.

Jewitt, C., \& Oyama, R. (2001). Visual meaning: A social semiotic approach.” In T. van Leeuwen \& C. Jewitt (Eds.), Handbook of Visual Analysis (pp. 134-156). London, UK: Sage Publications Ltd.

Kamali, M. (2016). Conceptualizing the "Other", Institutionalized Discrimination, and Cultural Racism. Department of Sociology University of Uppsala. Retrieved from http://cordis.europa.eu

Karim, K. (2006). "American Media's Coverage of Muslims: The Historical Roots of Contemporary Portrayals" in Poole, E. and Richardson, J. (Eds) Muslims and the News Media. (116-127). London, UK: I.B. Tauris.

Kelly, M. G. E. (2010). International biopolitics: Foucault, globalisation and imperialism. Theoria: $A$ Journal of Social and Political Theory, 57 (123), 1-26.

Kress, G. R., \& Van Leeuwen, T. (1996). Reading images: The grammar of visual design. London, UK: Routledge.

Lemke, J.L. (1990). Talking Science: Language, Learning, and Values. Santa Barbara, CA: Praeger Publishing Corporation.

Malkki, L. H. (1996). Speechless emissaries: Refugees, humanitarianism, and dehistoricization. Cultural anthropology, 11(3), 377-404.

Nakamura, L. (2002). Cybertypes: Race, Ethnicity, and Identity on the Internet. New York, USA: Routledge.

Philo, G., Briant, E., \& Donald, P. (2013). Bad News for Refugees. London, UK: Pluto Press.

Rane, H. (2010). Media Content and Inter-Community Relations, in Rane H., Ewart, J., \& Abdalla, M. (Eds.), Islam and the Australian News Media. (104-119) Carlton, Australia: Melbourne University Press.

Rane, H., Ewart, J., \& Martinkus, J. (2014). Media framing of the Muslim world: Conflicts, crises and contexts. London, UK: Palgrave Macmillan UK.

Said, E. W. (1979). Orientalism. London, UK: Penguin Books.

Said, E. W. (1981). Covering Islam: How the media and the experts determine how we see the rest of the world. New York, USA: Pantheon Books.

Said, E. W. (2000). Reflections on exile and other essays. Cambridge, UK: Harvard University Press.

Samei, M. (2010). Neo-orientalism? The Relationship between the West and Islam in our Globalised World. Third World Quarterly, 31(7), 1145-1160.

Slovic, P. (2007). "If I look at the Mass I will Never Act": Psychic Numbing and Genocide. Judgment and Decision Making, 2(2), 79-95. 
Small, D. A., \& Verrochi, N. M. (2009). The face of need: Facial Emotion Expression on Charity Advertisements. Journal of Marketing Research, 46(6), 777-787.

Tuastad, D. (2003). Neo-orientalism and the New Barbarism Thesis: Aspects of Symbolic Violence in the Middle East Conflict(s). Third World Quarterly, 24(4), 591-599.

van Schaik, R. (2016). Visual representations of (Syrian) refugees in European newspapers. (Master's Thesis). Malmo University, Sweden.

Wahl-Jorgensen, K. (2015, October 9). Humans of New York isn't journalism, but it helps us get beyond the headlines. NewStatesman. Retrieved from http://www.newstatesman.com 